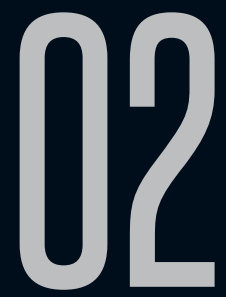

\title{
ENTREVISTA COM CELSO M. PACIORNIK, TRADUTOR DE H. P. LOVECRAFT
}

Júlio França

Marina Sena

Recebido em 18 abr 2017. Júlio França tem doutorado em Literatura Comparada Aprovado em 05 mar 2017. pela UFF (2006), com pós-doutorado pela Brown University (2015). É professor de Teoria da Literatura do Instituto de Letras e coordenador da área de Estudos de Literatura do Programa de Pós-graduação em Letras da UERJ. É líder do grupo de pesquisa Estudos do Gótico (CNPq) e integrante do GT da ANPOLL "Vertentes do Insólito Ficcional". Seus artigos mais recentes podem ser lidos na página "Sobre o Medo" (sobreomedo.wordpress.com). E-mail para contato: julfranca@gmail.com.

Marina Sena é bacharel em Letras (PortuguêsLiteraturas) e mestre em Teoria da Literatura, pela Universidade do Estado do Rio de Janeiro, onde atualmente é doutoranda em Teoria da Literatura e Literatura Comparada - sob a orientação do Prof. Dr. Júlio França. Também integra o Grupo de Pesquisa Estudos do Gótico (CNPq). E-mail para contato: marinafsena@gmail.com. 


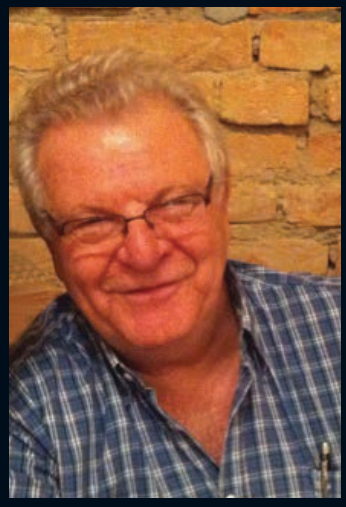

Celso Mauro Paciornik nasceu em Curitiba, em $1^{\circ}$ de janeiro de 1946. Estudou Engenharia, por um ano e meio, e Arquitetura, por três anos, mas não seguiu carreira em nenhuma das duas áreas. Em 1988, ele, que já ganhava a vida como tradutor, concluiu o curso de Português/Literaturas da Faculdade de Letras da USP. Desde então traduziu vários clássicos da literatura mundial, como $O$ espelho do mar (1998), de Joseph Conrad; Robinson Crusoé (2002), de Daniel Defoe; Luz em agosto (2008) e Absalão, Absalão! (2015), ambas de William Faulkner; Os infortúnios da virtude (2009), de Marquês de Sade. Já trabalhou para a maioria das grandes editoras do país: Cosac Naify, Companhia das Letras, Globo Livros, Estação Liberdade, Record, Ática, EdUSP, LPM, apenas para citar algumas. Pela editora lluminuras, Paciornik traduziu, de H. P. Lovecraft, o famoso ensaio, $O$ horror sobrenatural em literatura (2000), além de diversos contos que foram organizados em seis coletâneas: À procura de Kaddath (1998); A maldição de Sarnath (1998); Nas montanhas da loucura (1999); O horror Red Hook (2000); Dagon (2001); e A cor que caiu do céu (2003). Paciornik publicou o livro Inversos Tempos, pela Estação Liberdade, em 1992, uma coletânea de poemas escritos ao longo dos anos. Escreveu também uma tragicomédia musical intitulada Fantasia e Carnaval na República Brasil, que ganhou uma menção honrosa no concurso do Teatro de Natal (RN). Atualmente, trabalha para o jornal Estadão.

P.: O senhor poderia nos dar uma trajetória de sua vida profissional?

R.: Até conseguir chegar à tradução de clássicos da literatura, traduzi de tudo, do inglês, do francês, do espanhol. Livros técnicos, livros de sociologia, de história, livros infantis e infantojuvenis, livros de boa qualidade e muitos outros nem tanto, artigos para revistas, etc. Sem uma formação 
profissional acadêmica completa ou alguma profissão técnica durante boa parte da primeira metade da vida, a tradução se tornou o meu meio quase exclusivo de sobrevivência. Em razão de minha antiga paixão pela literatura, desde cedo persegui o objetivo de me tornar um tradutor literário mesmo sendo este um metiê mal remunerado em relação a outros ramos deste mesmo trabalho (traduções para empresas, tradutor juramentado, etc). Na verdade, minha preparação formal em idiomas estrangeiros não era muito grande e fui desenvolvendo os recursos de tradutor no calor, no sufoco e nos desafios dos trabalhos, o que não é algo a se recomendar a ninguém. O que me deu alguma estabilidade profissional foi trabalhar como tradutor contratado em jornais de São Paulo, primeiramente na Gazeta Mercantil, onde fiquei quatro anos e meio a partir de 1989, depois no Valor Econômico (três anos e meio) e mais recentemente e até agora, no Estadão (onde já estou há onze anos).

P.: Quais trabalhos seus o senhor julga mais importantes?

R.: É difícil estabelecer pessoalmente um juízo de valor neste caso. Com mais de 50 obras traduzidas (mais de 80 considerando os livros infantis e infantojuvenis), posso destacar, talvez, alguns trabalhos cujos autores inflariam o ego de qualquer tradutor, como William Faulkner, Joseph Conrad, Daniel Defoe, o Marquês de Sade, H.P. Lovecraft, mas o julgamento da qualidade desse esforço não caberia a mim e sim aos leitores e críticos da área.

P.: O senhor afirma, em outra entrevista, que sua primeira conexão com a literatura se deu em casa, uma vez que seus pais eram 
professores e leitores assíduos. Quais foram os primeiros livros da biblioteca de seus pais que o senhor se recorda de terem atraído a sua atenção?

R.: Como a maioria dos pequenos leitores de minha geração (nasci em 1946), comecei com Monteiro Lobato (Reinações de Narizinho, etc), adaptações que este fazia de clássicos como Robinson Crusoé, livros da Coleção Terra Mar e Ar (Aladim, aventuras, etc.), mais tarde os livros de Tarzan, Capitão Blood, $O$ pequeno príncipe, $O$ pequeno lorde, até Polyanna eu li, acredite. Depois Tom Sawyer, Huckleberry Finn, enfim. Difícil relembrar todos agora, 60 anos depois. Meus pais (meu pai especialmente) eram poliglotas e em casa havia livros em inglês, francês e espanhol, além do português, é claro. E ele assinava uma revista argentina chamada Leoplan, de variedades, mas que transcrevia romances e contos na íntegra em castelhano dos mais variados autores e tinha capas sedutoras. Quando eu cresci, tinha, portanto, uma ampla variedade de opções em diversas línguas para ler e curtir, o que não quer dizer que entendesse tudo que lia.

P.: O senhor traduziu uma coletânea de contos de autores norteamericanos, América (2001), que também conta com uma introdução sua. Como começou seu interesse pela literatura dos EUA? Lovecraft estava entre os autores lidos pelo senhor?

R.: Sempre houve muitas traduções de literatura norte-americana no Brasil (citei livros de Mark Twain, mas já havia traduções de Moby Dick, Hemingway, Edgar Allan Poe, livros policiais dos mais diversos autores, para não mencionar a longa lista 
de escritores da assim chamada fiç̧ão científica, da qual fui leitor assíduo, em particular de Ray Bradbury). Bradbury, aliás, do qual quase não havia traduções por aqui nos anos 60 , foi o primeiro a despertar meu desejo de traduzir (e arrisquei verter alguns de seus contos, com um resultado apenas regular). Havia muitas traduções também em português de Portugal, o que não era nenhuma barreira para quem quisesse ler e divertia encontrar algumas palavras que soavam de maneira estranha por aqui. Não seria nada difícil se encantar com estas literaturas e seus autores, sem prejuízo, é claro, dos autores europeus.

P.: A crítica costuma considerar Edgar A. Poe como a principal influência de H. P. Lovecraft. Comenta-se também a forte influência de Lord Dunsany, Arthur Machen e Algernon Blackwood. Que outras influências o senhor percebe na obra do autor, no que diz respeito ao estilo e à temática?

R.: Para ser honesto, destas possíveis influências de Lovecraft, só li Poe (praticamente a obra completa) e nada além, por isso teria dificuldade em responder a esta pergunta. Mas mesmo em relação a Poe, vejo a influência em Lovecraft mais na tentativa deste de criar um ambiente sinistro, assustador, insólito, muito embora Poe procurasse fazê-lo mais com as fantasias e terrores de seres humanos "normais" ou quase, e Lovecraft recorra quase sempre a criaturas abjetas e situações obscuras para instigar o medo e o horror. Neste sentido, Poe me parece tocar nas profundezas dos sentimentos, dos sofrimentos e dos êxtases humanos, o que não parece enquadrar o projeto de Lovecraft cujo universo 
e cujas criaturas aberrantes tentam chocar mais pela sua desumanidade, melhor dizendo, sua não humanidade. Talvez seja esse, enfim, o atrativo que motiva o reiterado "renascimento" deste autor no gosto de certo público.

P.: Lovecraft é conhecido por empregar um vocabulário pouco usual, frequentemente alambicado e hermético. Como o senhor lidou com essa característica da obra do autor, durante o processo de tradução?

R.: Eu apanhei um bocado para encontrar em português a profusão de adjetivos que o autor utiliza para criar seus mundos e situações. Aliás, em inglês é bem mais fácil enfileirar cinco, seis adjetivos numa mesma frase, o que não ocorre em português. Até hoje não sei até que ponto eu fui bem-sucedido na empreitada. Quando topei traduzir o primeiro livro para o editor Samuel Leon da Editora lluminuras, se não me engano "À procura de Kadath", não conhecia praticamente nada de Lovrecraft e não sabia da "fria" em que estava me metendo. Mas meio que em começo de carreira na tradução literária, e precisando urgentemente ganhar a vida, topei, e só depois fui descobrindo no que me metera. Mas o outro lado desse arroubo é que, depois da surpresa inicial, veio o desafio e a vontade de vencê-lo. E foi assim que, de adjetivo em adjetivo, de horror em horror, livro após livro, traduzi praticamente quase toda a obra de ficção de Lovecraft para a lluminuras. Mas a verdade é que temo reabrir os livros e descobrir que as traduções não ficaram tão boas como me pareceram no início. Relendo recentemente o conto "Dagon" que serve de título a um dos livros, fiquei relativamente bem impressionado com as 
soluções encontradas. Se o resto estiver assim, deste vexame acredito que escapei.

P.: A obra de Lovecraft é repleta de narradores em primeira pessoa, que entram em contato com seres, eventos ou locais que ultrapassam a compreensão humana. Em "O chamado de Cthulhu", por exemplo, ao descrever a cidade de R'yleh, que emerge das águas, o narrador menciona "superfícies grande demais para pertencerem a qualquer coisa normal ou própria desta Terra, corrompidas por imagens e hieróglifos terríveis" ["surfaces too great to belong to any thing right or proper for this earth, and impious with horrible images and hieroglyphs"]. Como é traduzir para uma outra língua algo que o próprio narrador afirma ser além da capacidade cognitiva do homem?

R.: Bem, se ele pôde criar essas impossibilidades, o tradutor também pode recriá-las em sua língua. No caso de traduzir Lovecraft, é preciso se deixar levar pelos seus voos tenebrosos com naturalidade, como se os assuntos fossem banais, corriqueiros. É o resultado do trabalho que terá de mostrar se o tradutor conseguiu captar os climas, as descrições, os sonhos e devaneios do autor em todo seu horror. Nesse sentido, traduzir Lovecraft pode ser cansativo pela adjetivação exacerbada e a descrição de criaturas e situações sem paralelo com as de nosso universo "normal", mas não é muito diferente de traduzir autores menos soturnos, ou menos prolixos. Aliás, toda obra literária estende uma série de armadilhas para o tradutor que terá de identificá-las e contorná-las. 
P.: Na tradução de $O$ Horror sobrenatural em literatura, o senhor fez a opção de traduzir "weird tale" por "história fantástica". Sabemos que weird é um termo de difícil tradução, mas o que Ihe motivou a escolha por "fantástico", termo com grande amplitude de usos no campo dos estudos literários?

R.: Vou passar esta resposta. Teria que reler a tradução para tentar identificar a particular escolha de termos, embora agora me pareça estranha esta particular escolha para "weird".

P.: O racismo e a xenofobia presentes na produção ficcional de Lovecraft são traços mencionados por diversos estudiosos. É possível observar a posição preconceituosa do escritor em diversos contos, como "O horror em Red Hook", em que os estrangeiros são descritos como "de aparência perversa" e relacionados a cultos satânicos, e "A rua", no qual uma rua é invadida por imigrantes que, supostamente, querem uma revolução e "esmagar a alma da velha América". Em "Ratos na parede", o gato do protagonista chama-se Nigger-man nome que o senhor optou por não traduzir. Essa característica do homem Lovecraft interferiu em seu trabalho de tradução da obra do escritor? O senhor acha que esse dado biográfico deveria interferir na apreciação estética da obra lovecraftiana?

R.: Evidentemente, não compartilho vários conceitos e todos os preconceitos de Lovecraft, e me agrada mais lidar com autores que não professem um racismo descarado ou algum outro preconceito que fira minha consciência. Mas como profissional deste ramo, nem sempre é possível escolher (aliás, quase nunca) o autor que se vai traduzir. É possível, quando muito, recusar-se 
a aceitar alguma obra cujo autor nos cause engulhos. No caso de Lovecraft, os preconceitos foram aparecendo aos poucos e não são visíveis na maioria dos contos. O próprio Faulkner, a quem tive a oportunidade de traduzir e é autor muito mais profundo, sério e "respeitável" que Lovecraft, não consegue ocultar certos preconceitos sulistas contra negros em algumas obras. Enfim, mesmo os preconceitos precisam ser vistos de um modo contextualizado. Senão, como traduzir os gregos antigos que não tinham o menor pudor em explorar escravos, ou a infinidade de autores que situam as mulheres num patamar inferior aos dos homens, para citar alguns exemplos. Portanto, acho que até certo ponto é possível abstrair certos preconceitos de determinados autores. Só não me peçam para traduzir Mein Kampf ou "Os Protocolos dos Sábios de Sião". Profissionalismo tem limite.

P.: A obra de Lovecraft é comumente dividida em três fases: Macabre stories, que faz referência ao início da carreira do escritor, The Dream-cycle, que corresponderia ao período, aproximadamente, de 1920 a 1927 e, por fim, Cthulhu Mythos - histórias que iriam de 1925 até o fim da carreira do escritor. O senhor identificou diferenças significativas de linguagem, entre esses e outros contos, que indicassem essas mudanças de fase do autor?

R.: A verdade é que, apesar de haver traduzido quase tudo de Lovecraft, não sou nenhum entendido ou especialista em sua obra, e inclusive desconhecia estas fases elencadas pelos estudiosos. Apenas fui traduzindo um volume após outro, sendo eles coletâneas de contos, sem uma preocupação com cronologias ou posicionamento no conjunto da obra. 
P.: Em diversos contos, os narradores de Lovecraft utilizam-se de uma linguagem cientificista para descrever seres, objetos, fatos e ambientes - muitos dos narradores lovecraftianos são eruditos, acadêmicos ou cientistas. Essa característica demandou algum trabalho de pesquisa específico durante o processo de tradução de alguns contos?

R.: Que eu me lembre, alguma pesquisa sim, e convém lembrar que na época não havia uma internet e um Google à disposição, - que dificultava sobremodo a pesquisa. Mas os arroubos eruditos ou científicos de Lovecraft não me pareceram muito profundos à época, sendo antes recursos para situar personagens e situações do que um real compromisso com a verdade científica ou algo do gênero.

P.: É notável o modo como Lovecraft e a mitologia por ele criada estão disseminadas na cultura pop, e sua importância pode ser medida pela quantidade e qualidade de artistas que the são tributários - Stephen King, Clive Barker, Ridley Scott, Guillermo Del Toro, John Carpenter, Alan Moore, Neil Gaiman, H. R. Giger, para citar apenas alguns. Em sua opinião, por que, 80 anos após a sua morte, Lovecraft tornou-se mais lido do que nunca?

R.: A verdade é que, embora reconheça a influência exercida por Lovecraft sobre a cultura pop e muitos criadores nas áreas de cinema, literatura e artes visuais (uma simples Googlada em Cthulhu, imagens, dá uma noção da multiplicidade de manifestações em torno de um "monstro" cujo nome, segundo o próprio autor, é quase impronunciável), não tenho dados para corroborar a evolução de seu público leitor. Só sei que, 
depois de traduzir alguns contos do autor, quando perguntei ao Samuel Leon, da lluminuras, que contratara o trabalho e tem grande experiência editorial e conhecimento do público leitor, se fazia sentido do ponto de vista editorial reeditar todo o Lovecraft, ele me garantiu que este tem um público cativo que se renova a cada geração. Uma pequena prova disso é que boa parte dos volumes lançados pela lluminuras foi reimpressa com novas capas mais chamativas e existem várias outras traduções no mercado. 